\title{
ONLINE MONITORING OF SOFT SENSOR PERFORMANCE: A CASE STUDY OF CEMENT CLINKER QUALITY PARAMETERS SOFT SENSOR
}

\author{
Nsidibe-Obong Ekpe Moses $^{1}$, Sunday Boladale Alabi ${ }^{2}$ \\ ${ }^{1}$ Department of Chemical Engineering, Federal University of Petroleum Resources, Effurun, Delta State, Nigeria \\ ${ }^{2}$ Department of Chemical and Petroleum Engineering, University of Uyo, Uyo, Nigeria
}

\begin{abstract}
The predictive ability of soft sensors deteriorates over time due to changes in the state of the plant and process characteristics. The results from the offline laboratory analyses of samples can be used to determine when a soft sensor requires recalibration; however, this approach is time-consuming. This paper presents a systematic approach in which a reverse model is developed for an online monitoring of the performance of soft sensor, the forward model. The proposed methodology is illustrated using a cement clinker quality parameters soft sensor as a case study. The reverse regression model gave rise to root mean squared error, coefficient of determination and worst case relative error values of 17.436, 0.9999 and 4.59\%, respectively. Thus, it was concluded that, instead of the time-consuming approach of taking samples at the kiln exit for laboratory analysis, the developed reverse model can be used to provide plant operators with information about the predictive accuracy of the soft sensor.
\end{abstract}

Keywords: Online Monitoring, Performance, Soft Sensor, Cement Clinker, Quality Parameters.

\section{INTRODUCTION}

A soft sensor is a mathematical model that correlates process state and product quality variables that are difficult to measure online with frequently available process measurements. Soft sensors can be easily integrated with control systems to provide tighter process performance [1]. A soft sensor provides real-time, accurate predictions of product quality variables, eliminating additional energy and production cost associated with out-of-specification products. Also, it can monitor processes, design tighter control, provide fault detection and diagnosis [2]. In comparison to hardware sensors (analyzers) for online estimation of product quality parameters, soft sensor is cheaper and has found applications in many industries including the cement industry. However, the predictive ability of soft sensors deteriorates over time due to changes in process characteristics. To maintain soft-sensors performance for a longer period of time, model parameters have to be re-tuned in an online manner by adaptive methods such as recursive principal component analysis, PCA [3], local methods [4] and recursive principal least square regression, PLS [5]. The recursive methods can adapt the model automatically to new operating conditions but they are known to function well only with slow changes in process characteristics and, if the global model is linear, only with mild nonlinearities [6]. Local techniques are globally nonlinear, can achieve the required accuracy and can be promptly upgraded to automatically include new operations. These methods are reported in [6], [7] as tools for calibrating or reconstructing the failing soft sensor. Unfortunately, there are no reports on how to determine when the failing soft sensor model requires reconstruction or calibration.
Therefore, this study develops a general-purpose framework for online monitoring of the performance of soft sensor. The proposed framework is then applied to a cement clinker quality parameters soft sensor, as a case study. The findings are expected to aid in the decision making to improve the predictive accuracy of the soft sensor and subsequently help determine when the soft sensor model should be updated or rebuilt.

\section{METHODOLOGY}

Sensor failure can be defined as an unpermitted deviation from the acceptable condition of at least one characteristic property or parameter of the system obtained by the sensor [8]. To determine sensor failure, a systematic approach is proposed here for online monitoring of the soft sensor performance.

Suppose the performance of a multiple-input-multipleoutput (MIMO) soft sensor (model) with inputs $x_{s 1}, x_{s 2}, x_{s 3} \ldots x_{s n}$ and outputs $y_{s 1}, y_{s 2}, y_{s 3} \ldots y_{s n}$ is to be monitored online. The systematic approach proposed here employs a companion or reverse model that uses the outputs of the soft sensor as inputs to predict at least one of the soft sensor's inputs (parameters) as shown in figure 1.

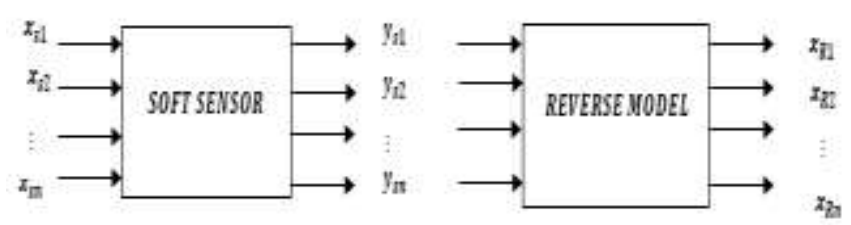

Fig -1: Monitoring soft sensor performance with a reverse model 
where $x_{R 1}, x_{R 2}, x_{R 3} \ldots x_{R n}$ are the reverse model estimated values of the soft sensor inputs. These estimated values are compared with the original input values to the soft sensor based on some performance criteria. Thereafter, a decision is made about the state of the soft sensor, depending on the magnitude of the deviation or performance criterion.

In summary, the proposed systematic procedure of applying reverse modelling technique for monitoring soft sensor performance comprises of the following steps:

1. Use the same datasets from which the soft sensor was built to develop the reverse model.

2. For known values of the input to the soft sensor $\boldsymbol{x}_{\boldsymbol{s}}$, determine the values of the output from the soft sensor $\boldsymbol{y}_{\boldsymbol{s i}}$.

3. Use the values of the output of the soft sensor as input to the reverse model and determine the output values of the reverse model $\boldsymbol{x}_{\boldsymbol{R} i}$.

4. Compare the reverse model predictions $\boldsymbol{x}_{\boldsymbol{R} \boldsymbol{i}}$, with the measured input values $\boldsymbol{x}_{\boldsymbol{s i}}$. Based on the maximum permissible error value, a decision on whether the soft sensor is active or failing can be reached.

The above procedures are applied to datasets collected from the simulation of first principle-based cement rotary kiln model. The results are given in section 3 .

\section{CASE STUDY}

The soft sensor whose performance is to be monitored online by the proposed reverse model was reported in [14]. The steps followed in developing the reported soft sensor are summarised in section 3.1. Section 3.2 gives a detailed description of the implementation of the proposed reverse model for online monitoring of cement clinker quality parameters soft sensor.

\subsection{Summary of Soft Sensor Development}

The cement clinker quality parameters soft sensor under study, was developed by performing statistically designed experiment on cement rotary kiln first principle-based model. Thereafter, the experimental (simulation) data obtained were used to build the soft sensor. Equations (1-14) is the first principle-based cement rotary kiln model.

\subsubsection{Steady State Material Balance Equations}

The equations that describe the one-dimensional steady-state axial evolution of components involved in the clinker formation are given as equations (1) - (9) [9], [10], [11].

\section{Calcium Carbonate (Lime Stone)}

$$
\begin{aligned}
& \mathrm{CaCO}_{3}: \frac{d m_{\mathrm{CaCO}_{3}}}{d z}=-\frac{1}{v_{s}} r_{\mathrm{CaCO}_{3}} \cdot \mathrm{M}_{\mathrm{CaCO}_{3}} \\
& =\text {-1vs[MCaCO3MCaOKCaCO3exp-ECaCO3R.TsmCa } \\
& \text { CO3]. }
\end{aligned}
$$

\section{Calcium Oxide (Quick lime)}

$$
\begin{aligned}
& \mathrm{CaO}: \frac{d m_{\mathrm{CaO}}}{d z}=\frac{1}{v_{S}}\left(r_{\mathrm{CaCO}_{3}}-r_{c_{2} S}-r_{C_{3} S}-r_{C_{3} A}-r_{C_{4} A F}\right) \\
& \frac{1}{v_{S}}\left[K_{\mathrm{CaCO}_{3}} \exp \left[-\frac{E_{\mathrm{CaCO}_{3}}}{R \cdot T_{S}}\right] m_{\mathrm{CaCO}_{3}}-\right. \\
& K_{C_{2} S} \exp \left[-\frac{E_{C_{2} S}}{R \cdot T_{S}}\right] m^{2}{ }_{\mathrm{CaO}} m_{\mathrm{SiO}_{2}}- \\
& K_{C_{3} S} \exp \left[-\frac{E_{C_{3} S}}{R \cdot T_{S}}\right] m_{C a O} m_{c_{2} S}- \\
& K_{C_{3} A} \exp \left[-\frac{E_{C_{3} A}}{R \cdot T_{S}}\right] m^{3}{ }_{C a O} m_{A l_{2} O_{3}}- \\
& \left.K_{C_{4} A F} \exp \left[-\frac{E_{C_{3} A}}{R \cdot T_{S}}\right] m^{4}{ }_{C a O} m_{\mathrm{Al}_{2} \mathrm{O}_{3}} m_{\mathrm{Fe}_{2} \mathrm{O}_{3}}\right] \text {. }
\end{aligned}
$$

\section{Silicon (IV) Oxide (Silica)}

$$
\begin{aligned}
\mathrm{SiO}_{2}: & \frac{d m_{\mathrm{SiO}_{2}}}{d z}=-\frac{1}{v_{s}} r_{c_{2} S} \cdot M_{\mathrm{SiO}_{2}} \\
= & -\frac{1}{v_{S}}\left[\frac{M_{\mathrm{SiO}_{2}}}{2 M_{\mathrm{CaO}}} K_{C_{2} S} \exp \left[-\frac{E_{C_{2} S}}{R \cdot T_{S}}\right] m^{2} \mathrm{CaO}_{\mathrm{SiO}_{2}} m\right.
\end{aligned}
$$

\section{Aluminum Oxide (Alumina)}

$$
\begin{aligned}
& \mathrm{Al}_{2} \mathrm{O}_{3}: \frac{d m_{A l_{2} O_{3}}}{d z}=-\frac{1}{v_{S}}\left(r_{C_{4} A F}+r_{C_{3} A}\right) \cdot M_{A_{2} O_{3}} \\
&= \\
&-\frac{1}{v_{s}}\left[K_{C_{4} A F} \exp \left[-\frac{E_{C_{3} A}}{R \cdot T_{S}}\right] m_{C a O}^{4} m_{A_{2} O_{3}} m_{F_{2} O_{3}}+\right. \\
& \text { KC } 3 A \exp -E C 3 A R . T S \text { m3CaOmAl2O3. }
\end{aligned}
$$$$
\text { (4) }
$$

\section{Iron (III) Oxide}

$$
\begin{aligned}
& \mathrm{Fe}_{2} \mathrm{O}_{3}: \frac{d Y_{\mathrm{Fe}_{2} \mathrm{O}_{3}}}{d z}=-\frac{1}{v_{S}} r_{C_{4} A F} \cdot M_{\mathrm{Fe}_{2} \mathrm{O}_{3}} \\
= & -\frac{1}{v_{S}}\left[\frac{M_{\mathrm{Fe}_{2} \mathrm{O}_{3}}}{M_{\mathrm{CaO}}} K_{C_{4} A F} \exp \left[-\frac{E_{C_{3} A}}{R \cdot T_{s}}\right] m_{\mathrm{CaO}}^{4} m_{\mathrm{Al}_{2} \mathrm{O}_{3}} m_{\mathrm{Fe}_{2} \mathrm{O}_{3}}\right] .
\end{aligned}
$$

\section{Dicalcium Silicate (Belite, $\mathrm{C}_{2} \mathrm{~S}$ )}

$$
\begin{aligned}
& \mathrm{C}_{2} \mathrm{~S}: \frac{d Y_{C_{2} S}}{d z}=\frac{1}{v_{s}}\left(r_{C_{2} S}-r_{C_{3} S}\right) \cdot M_{C_{2} S} \\
& \frac{d Y_{C_{2} S}}{d z}=\frac{1}{v_{S}}\left(K_{C_{2} S} \exp \left[-\frac{E_{C_{2} S}}{R \cdot T_{S}}\right] m^{2}{ }_{\mathrm{CaO}} m_{\mathrm{SiO}_{2}}-\right. \\
& \text { KC3Sexp-EC3SR.TsmCaOmc2s.MC2SMCa } \\
& \text { O. }
\end{aligned}
$$

\section{Tricalcium Silicate (Alite, $\mathrm{C}_{3} \mathrm{~S}$ )}

$$
\begin{aligned}
\mathrm{C}_{3} \mathrm{~S}: \frac{d Y_{C_{3} S}}{d z} & =\frac{1}{v_{s}} r_{C_{3} S} \cdot M_{C_{3} S} \\
= & \frac{1}{v_{s}}\left(K_{C_{3} S} \exp \left[-\frac{E_{C_{3} S}}{R \cdot T_{S}}\right] m_{C a O} m_{c_{2} S}\right) \cdot \frac{M_{C_{2} S}}{M_{C a O}} .
\end{aligned}
$$

\section{Tricalcium Aluminate (Celite, $\left.\mathbf{C}_{3} \mathrm{~A}\right)$}

$$
\begin{aligned}
\mathrm{C}_{3} \mathrm{~A} & : \frac{d Y_{C_{3} A}}{d z}=\frac{1}{v_{s}} r_{C_{3} A} \cdot M_{C_{3} A} \\
& \frac{d Y_{C_{3} A}}{d z} \\
& =\frac{1}{v_{s}}\left(K_{C_{3} A} \exp \left[-\frac{E_{C_{3} A}}{R \cdot T_{s}}\right] m^{3}{ }_{\mathrm{CaO}} m_{\mathrm{Al}_{2} \mathrm{O}_{3}}\right) \cdot \frac{M_{C_{3} A}}{M_{\mathrm{CaO}}} .
\end{aligned}
$$




\section{Tetracalcium Aluminoferrite $\left(\mathrm{C}_{4} \mathrm{AF}\right)$}

$$
\begin{gathered}
\mathrm{C}_{4} \mathrm{AF}: \frac{d Y_{C_{4} A F}}{d z}=\frac{1}{v_{s}} r_{C_{4} A F} \cdot M_{C_{4} A F} \\
\frac{d Y_{C_{4} A F}}{d z}=\frac{1}{v_{s}}\left(K_{C_{4} A F} \exp \left[-\frac{E_{C_{3} A}}{R \cdot T_{S}}\right] m_{\mathrm{CaO}^{4}} m_{\mathrm{Al}_{2} \mathrm{O}_{3}} m_{\mathrm{Fe}_{2} \mathrm{O}_{3}}\right) \cdot \frac{M_{C_{3} A}}{M_{\mathrm{CaO}}} .
\end{gathered}
$$

\subsubsection{Steady State Energy Balance Equations}

The energy balance equations that describe the onedimensional steady-state axial temperature profiles of the phases involved in clinker formation are given as equations (10) - (12) [12].

\section{Gas (Free Board) Phase}

$A_{g} C_{p g} \rho_{g} v_{g} \frac{d T_{g}}{d z}=\beta_{G \rightarrow w}\left(T_{w}-T_{g}\right)+\beta_{S \rightarrow G}\left(T_{s}-T_{g}\right)+$

$Q_{\text {comb }}$.

\section{Solid (Bed) Phase}

$A_{s} C_{p s} \rho_{s} v_{s} \frac{d T_{s}}{d z}=\beta_{S \rightarrow G}\left(T_{g}-T_{s}\right)+\beta_{W \rightarrow S}\left(T_{w}-T_{s}\right)-$ $\left(r_{\mathrm{CaCO}_{3}} \cdot \Delta H_{\mathrm{CaCO}_{3}}+r_{C_{2} S} \cdot \Delta H_{C_{2} S}+r_{C_{3} S} \cdot \Delta H_{C_{3} S}+\right.$ rC3A. $\triangle H C 3 A+r C 4 A F . \triangle H C 4 A F$.

(11)

\section{Wall Phase}

$\beta_{G \rightarrow w}\left(T_{g}-T_{w}\right)+\beta_{W \rightarrow S}\left(T_{s}-T_{w}\right)+\beta_{W \rightarrow \text { Air }}\left(T_{a}-T_{w}\right)=0$.

The residence time and velocity of the solid materials within the rotary kiln are described by equations (13) - (14) [11].

Velocity of the solid,

$v_{s}=\frac{\alpha D n}{60 \times 1.77 \sqrt{\beta}}$.

Material residence time,

$$
\tau=\frac{1.77 L \sqrt{\beta}}{\alpha D n} .
$$

Where, the heat transfer coefficients $\left(\beta_{G \rightarrow w}, \beta_{s \rightarrow G} \beta_{W \rightarrow s}, \beta_{w \rightarrow \text { Air }}\right)$, heat released by fuel combustion $\left(Q_{\text {comb }}\right)$, enthalpy of the chemicals $\left(\Delta H_{i}\right)$ and other parameters where obtained from [9], [10], [12].

\subsubsection{Experimental Design}

Data in the range of the plant's operating conditions and the values of some process parameters for a typical cement manufacturing plant were obtained from [10], [12] and [13]. The operating conditions used for the simulation are as shown in table 1.
Table 1: Operating conditions for simulation of the cement rotary kiln

\begin{tabular}{|c|c|c|c|c|}
\hline S/N & $\begin{array}{c}\text { Raw Meal } \\
\text { Quality }\end{array}$ & $\begin{array}{c}\text { Operating } \\
\text { Conditions }\end{array}$ & $\begin{array}{c}\text { Kiln } \\
\text { Operating } \\
\text { Variables }\end{array}$ & $\begin{array}{c}\text { Operating } \\
\text { Conditions }\end{array}$ \\
\hline 1 & $\begin{array}{c}\text { Quick } \\
\text { Lime } \\
(\mathrm{CaO})\end{array}$ & $0.30-0.50$ & $\begin{array}{c}\text { Kiln Feed } \\
\text { Rate, } \dot{m}_{s} \\
(\mathrm{~kg} / \mathrm{s})\end{array}$ & $35-45$ \\
\hline 2 & $\begin{array}{c}\text { Silicon } \\
\text { (IV) Oxide }\end{array}$ & $0.10-0.20$ & $\begin{array}{c}\text { Feed Inlet } \\
\text { Temperatu } \\
\text { re, } \dot{T}_{s}(\mathrm{~K})\end{array}$ & $990-1120$ \\
\hline 3 & $\begin{array}{c}\text { Aluminum } \\
\text { Oxide }\end{array}$ & $0.02-0.05$ & $\begin{array}{c}\text { Fuel Feed } \\
\text { Rate, } \dot{m}_{f} \\
(\mathrm{~kg} / \mathrm{s})\end{array}$ & $1.5-1.9$ \\
\hline & $\begin{array}{c}\text { Iron (III) } \\
\text { Oxide }\end{array}$ & $0.01-0.04$ & $\begin{array}{c}\text { Mass Flow } \\
\text { rate of } \\
\text { Air, } \dot{m}_{a} \\
(\mathrm{~kg} / \mathrm{s})\end{array}$ & $27-33$ \\
\hline
\end{tabular}

With these operating conditions, a central composite response surface design (with $1 / 2$ fraction) was used to generate one hundred and fifty four (154) data points. These data points were then entered into the rotary kiln simulation platform to determine the response variables for a combination of the inputs/factors.

Furthermore, with the aid of Design Expert 7.0 statistical tool, these 154 data points were then used (after outlying data points had been removed based on the method described in [14]) to build the regression model (soft sensor). The soft sensor is of the form:

$R=a_{0}+a_{1} x_{1}+a_{2} x_{2}+a_{3} x_{3}+\cdots+a_{12} x_{1} x_{2}+$
$a_{13} x_{1} x_{3}+\cdots+a_{11} x_{1}^{2}+a_{22} x_{2}^{2}+\cdots$

where $R$ is the estimated response variable (clinker quality parameters): Lime Saturation Factor (LSF), Silica Moduli (SM), Alumina Moduli (AM), Free Lime (FCaO) and Alite $\left(\mathrm{C}_{3} \mathrm{~S}\right) ; x_{1}, x_{2}, x_{3} \ldots$ are the input parameters $\left(\mathrm{CaO}, \mathrm{SiO}_{2}\right.$, $\mathrm{Al}_{2} \mathrm{O}_{3}, \mathrm{Fe}_{2} \mathrm{O}_{3}$, mass flow rate of solid, feed inlet temperature, mass flow rate of fuel and mass flow rate of air), $a_{0}$ represents the mean (intercept); $a_{1}, a_{2}, a_{3} \ldots$ are the linear effects; $a_{11}, a_{22}, a_{33} \ldots$ are the quadratic effects while $a_{12}, a_{13}, a_{23} \ldots$ are the interaction effects.

\subsection{Reverse Model Development and}

\section{Implementation}

Clinker samples at the kiln exit may be taken to the laboratory for quality parameters analysis to verify the prediction ability of the soft sensor. The problem of large measurement delay necessitates the development of a model which uses the predictions (clinker quality parameters) to estimate at least one of the corresponding easy-to-measure kiln operating variables. Any significant difference between reverse model predictions and the corresponding measured kiln operating input variable of interest may necessitate reconstruction of the soft sensor (see figure 2). 


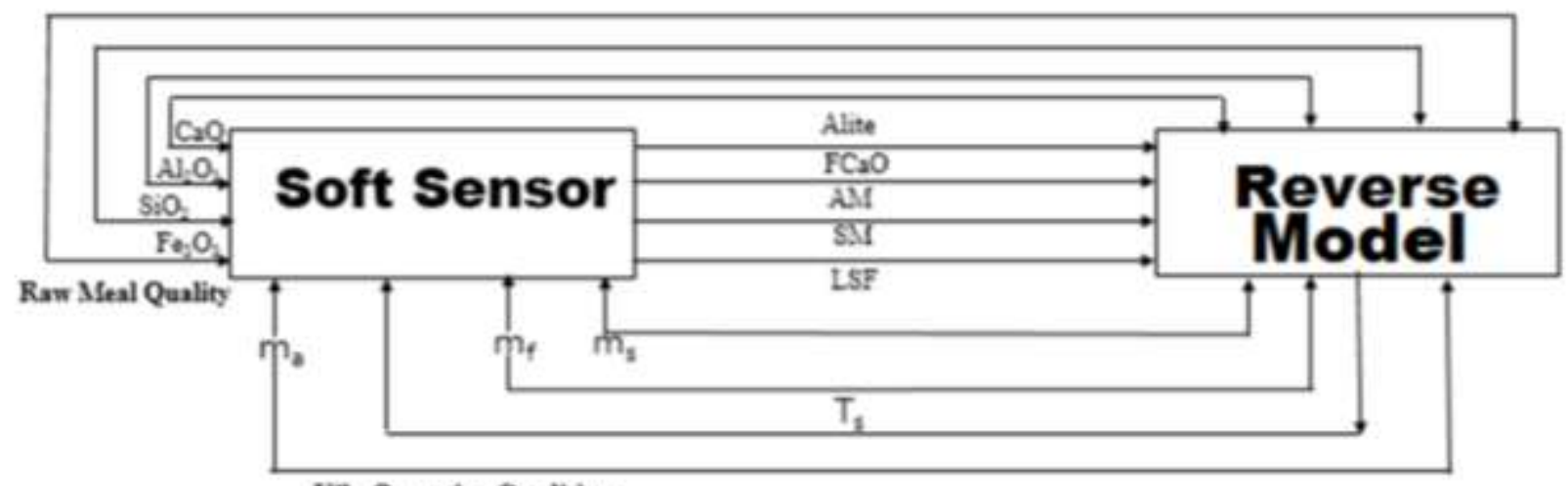

Kile Operatiag Conditions

Fig -2: Monitoring the performance of clinker quality parameters soft sensor using a reverse model

In this study, the reverse model was built using the same data set used for building the eight (8)-input-five (5)-output soft sensor (model). The inputs to the reverse model are: the four (4) raw meal parameters $\left(\mathrm{CaO}, \mathrm{SiO}_{2}, \mathrm{Al}_{2} \mathrm{O}_{3}\right.$ and $\left.\mathrm{Fe}_{2} \mathrm{O}_{3}\right)$, three (3) out of the four (4) kiln operating variables $\left(\dot{m}_{\mathrm{s}}, \dot{\mathrm{m}}_{\mathrm{f}}, \dot{\mathrm{m}}_{\mathrm{a}}\right)$ and the five (5)-clinker quality parameters (LSF, SM, AM, FCaO, $\mathrm{C}_{3} \mathrm{~S}$ ). With the steps outlined below, (for building the soft sensor), these inputs were used to predict the feed inlet temperature of the kiln $\left(\dot{T}_{s}\right)$.

The following steps in Design Expert 7.0 software were used to build this model:

- The values of the responses (for each design run) in the simulation platform were copied into the central composite design layout view of the Design Expert software.

- Each response variable was transformed for cases where the ratio of maximum to minimum response value was above 10 . Otherwise, transformation was not necessary.

- The fit summary environment was viewed to access information about the goodness of fit of the model (such as degree of freedom, F-value, P-value) and the model summary statistics (such as standard deviation, $\mathrm{R}^{2}$ adj, PRESS). Also, it gives information on which model is aliased. With Ftest, one can know if a group of variables are jointly significant. P-value, which must be less than the alpha level is the probability that the results have happened by chance. Predicted Residual Error Sum of Squares (PRESS) statistic estimates how the model performs on hold-out data, using only in-sample data [15].

- $\quad$ Backward elimination regression (with alpha $=0.05$ ) was employed at model process order (which could be linear, 2FI, quadratic, cubic) for automatic elimination of undesired model terms.

- Analysis of variance (ANOVA) platform which analyzes the chosen model gave a view of the results of analysis.

- Diagnostic platform which evaluates the model fit and transformation choice with graphs (such as normal plot, residual vs prediction, etc.) was viewed to make the final choice on the model type.
In addition to the above-stated statistical criteria, the performance of the model developed in this study was determined by evaluating the percent relative error $\left(\varepsilon_{r}\right)$, coefficient of determination $\left(\mathrm{R}^{2}\right)$ and the root mean of squared error (RMSE) values produced by the model to the trained data (i.e. data used to build the model) and untrained data (i.e. data different from the model data). The equations (16-18) were used to calculate the above mentioned performance criteria.

$$
R M S E=\sqrt{\frac{\sum_{i=1}^{n}\left(y-y_{p}\right)^{2}}{n}}
$$

where, $y_{P}$, is the predicted value of the independent variable and $\mathrm{y}$ is the simulated value.

$$
\begin{aligned}
& \varepsilon_{r}=\frac{\mid \text { Actual }- \text { Predicted } \mid}{\text { Actual }} \times 100 \\
& R^{2}=1-\frac{\sum_{i=1}^{n}\left(y-y_{p}\right)^{2}}{\sum_{i=1}^{n}(y-\bar{y})^{2}}
\end{aligned}
$$

\subsubsection{Reverse Model Performance Evaluation}

Interpolation test (datasets different from the original datasets used to build the model but within the range of the plant's operating conditions) was performed to evaluate the performance of the reverse model. The data was obtained through two (2)-level factorial design (Res IV) to evaluate the performance of the model. The model predictions were compared with the first principle-based simulation data used for building the model.

\subsubsection{Results and Discussion}

\subsubsection{Estimation Capability of the Reverse Model}

The multiple-input-single-output reverse (second order regression) model having the potentials for monitoring the performance of the soft sensor is given in equation (19). Table 2 shows the performance of the reverse model. 
Table -2: Performance of the reverse model

\begin{tabular}{|c|c|c|c|c|}
\hline $\begin{array}{c}\text { Model } \\
\text { Type }\end{array}$ & $\begin{array}{c}\text { Worst- } \\
\text { Case } \\
\text { Relative } \\
\text { Error }\end{array}$ & RMSE & $\mathrm{R}^{2}$ & $\begin{array}{c}\text { Interpolation } \\
\text { Test } \\
\text { (Maximum } \\
\text { \% Relative } \\
\text { Error) }\end{array}$ \\
\hline Quadratic & 4.59 & 17.436 & 0.9999 & 4.83 \\
\hline
\end{tabular}

$\boldsymbol{F}=1010.10876+935.99688 * A+2155.27204 * B+$ $15208.26768 * C+8772.25489 * D+2.86582 * E-$ $919.59003 * G-4.05511 * H+0.92872 * L S F-$ $11.15669 * S M-23.73571 * A M+14.18909 * \mathrm{FCaO}+$ $7.16906 *\left(C_{3} S\right)-21699.43573 * A * C+7419.02111 * A$ $* D-10.04479 * A * E-9.53823 * A * S M+42.00079 *$ $A * A M-14.06879 * A * F C a O-21951.12021 * B * C-$ $60.32698 * B * E+1086.08576 * B * G-42.48767 * B *$ $H-2.44172 * B * L S F+23.88024 * B * F C a O-44.61101$ $* B *\left(C_{3} S\right)+143.48303 * C * E-385.25341 * C *$ $H+38.37239 * C * L S F+353.43583 * C * S M+$ $289.47393 * C * A M-92.81846 * C * F C a O+91.32457$ $* C *\left(C_{3} S\right)+330.39683 * D * E-12863.51311 * D * G$ $+320.08797 * D * H-336.47638 * D * S M-20.22942 *$ $D * A M+210.4378 * D * F C a O+6.83205 * E * G-$ $0.50337 * E * H+0.80686 * E * S M-0.24707 * E *$ $\mathrm{FCaO}+0.38212 * E *\left(C_{3} S\right)+29.14296 * G * H-$ $15.14362 * G * S M-17.66147 * G * A M+4.25904 * G *$ $\mathrm{FCaO}-5.93557 * G *\left(C_{3} S\right)-0.083247 * H * L S F+$ $0.92156 * H * A M-0.51454 * H * F C a O+0.054188 * H$ $*\left(C_{3} S\right)-0.035894 * L S F * S M-0.095144 * L S F * A M-$ $0.62118 * S M * A M+0.40745 * S M * F C a O-0.14122 *$ $S M *\left(C_{3} S\right)+0.42843 * A M * F C a O+0.027997 * A M *$ $\left(C_{3} S\right)-0.15805 * \mathrm{FCaO} *\left(C_{3} S\right)-289990 * D^{2}+$ $0.00669147 * L S F^{2}+0.033111 * S M^{2}-0.010626 *$ $\mathrm{FCaO}^{2}+0.056167 *\left(\mathrm{C}_{3} \mathrm{~S}\right)^{2}$

The reverse model (4) is a relationship between the feed inlet temperature (an inlet condition of the forward model), the clinker quality parameters and some of the input variables of the forward model.

The performance of this model was evaluated by comparing its predictions with the simulated data. Using the statistical criteria earlier mentioned, the model is found to be accurate with coefficient of determination, $\mathrm{R}^{2}=0.9999$. Moreover, the model predictions have worst case relative error of $4.59 \%$ which is deemed accurate enough for practical applications. In addition, the interpolation ability of the reverse model was tested with the same data used for evaluating the forward (soft sensor) model. The estimated temperature from the reverse regression model closely matches simulated feed inlet temperature with worst case relative error of $4.83 \%$. Although, this error level has to be taken into consideration during its online monitoring of the forward model, the reverse model is deemed adequate for online monitoring of the forward model (soft sensor).

The developed regression model monitors the performance of the soft sensor (forward model) by predicting the feed inlet temperature of the rotary kiln. Therefore, the reverse model has the potential to deal with the time-consuming and labour-intensive approach of taking samples at the kiln outlet on weekly or monthly basis. This is usually done to determine if there are changes in process characteristics which could necessitate the soft sensor recalibration.

\section{CONCLUSION}

The predictive ability of soft sensors deteriorates over time due to changes in the state of the plant and process characteristics. For effective quality control, it is important to determine when the soft sensor requires recalibration. This paper presents a systematic approach for online monitoring of the soft sensor performance. The proposed methodology was illustrated through its application to a cement clinker quality parameters soft sensor. The case study reveals the effectiveness of the systematic framework in developing a reverse model for online monitoring of the performance of soft sensor developed for cement clinker quality parameters. The reverse regression model gave rise to root mean squared error, coefficient of determination and worst case relative error values of 17.436, 0.9999 and $4.59 \%$, respectively. Thus, it is concluded that, instead of the labour-intensive approach of taking samples at the kiln exit for laboratory analysis, the developed reverse model can provide plant operators with information about the performance of the soft sensor and subsequently help determine when the soft sensor should be updated or rebuilt.

\section{REFERENCES}

[1] A. Bradley, "PlantPAx, Model Builder Enable Realtime Monitoring and Process Prediction," Rockwell Automation, Inc., USA. 2011. http:// www.rockwellautomation.com.

[2] B. Huang, "Improve Measurement with Soft Sensors for Process Industries," Presentation at ISA Fort McMurray, 18th April, 2011.

[3] Li, W., Yue, H., Valle-Cervantes, S. and Qin, S. (2000). Recursive PCA for adaptive process monitoring [J]. Process Control, 10 (5): 471-486.

[4] G. Bontempi, G. Birattari, and M. Bersini, "Lazy learning for Local Modeling and Control Design," International Journal of Control, 1999, 72: 179-186.

[5] S. J. Qin, "Recursive PLS algorithms for adaptive data modeling," Computers and Chemical Engineering, 1998, 22 (4), 503-514.

[6] Z. B. Zhu, Z. H. Song and A. Palazoglu, "Transition process modeling and monitoring based on dynamic ensemble clustering and multiclass support vector data description," Industrial \& Engineering Chemistry Research, 2011,50:13969-13983.

[7] H. Kaneko and K. Funatsu, "Application of Online Support Vector Regression for Soft Sensors," AIChE J 2013, 60:600-612.

[8] H. Alwi, C. Edwards and C. Tan, "Fault Tolerant Control and Fault Detection and Isolation. In Fault Detection and Fault-Tolerant Control Using Sliding Modes," Advances in Industrial Control, Springer London, 2011, pp. 7-27.

[9] Darabi, P. (2007) A mathematical Model for Cement 
Kilns, published M. Sc. Thesis in Mechanical Engineering, The University of British Columbia, Vancouver, Canada.

[10] Mastorakos, E., Massias, A., Tsakiroglou, C.D, Goussis, D. A, Burganos, V.N, and Payatakes, A. C. (1999) CFD predictions for cement kilns including flame modelling, heat transfer and clinker chemistry, Appl. Math. Model. 23, 55-76. http://dx.doi.org/10.1016/S0307-904X(98)10053-7

[11] Zhuo W., Tian-ran, W., Ming-zhe, Y.and Hong, W. (2008) Dynamic Model for Simulation and Control of Cement Rotary Kilns [J]. System Simulation, 20, 51315135.

[12] Sadighi, S, Shirvani, M. and Ahmad, A. (2011) Rotary Cement Kiln Coating Estimator: Integrated Modelling of Kiln with Shell Temperature Measurement. Can. J. Chem. Eng. 89,116-125. http://dx.doi.org/10.1002/cjce.20365

[13] Mintus, F., Hamel, S. and Krumm, W. (2006) Wet process rotary cement kilns: Modeling and Simulation. J. Clean Techn. Environ. Policy (S1618-9558), 8, 112122. http://dx.doi.org/10.1007/s10098-006-0039-6

[14] N. E. Moses and S. B. Alabi, "Predictive Model for Cement Clinker Quality Parameters," Journal of Materials Science and Chemical Engineering. 4, 84100, 2016. http://dx.doi.org/10.4236/msce.2016.47012

[15] N. Zumel, "Estimating Generalization Error with the PRESS statistic,"2014. http://www.winvector.com/blog/2014/09/estimating-generalizationerror-with-the-press-statistic/

\section{BIOGRAPHIES}

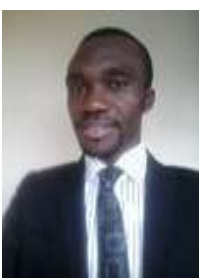

Nsidibe-Obong E. Moses received his B.Eng. (2007) degree in Chemical Engineering from Federal University of Technology Owerri, Imo State. He is currently on a Masters degree programme (Chemical Engineering) at the University of Uyo, Uyo, Akwa Ibom State, Nigeria.

Mr. Moses's research interest include chemical/biochemical process analysis, modelling, simulation and control. He is a Member of the Nigerian Society of Chemical Engineers (MNSChE).

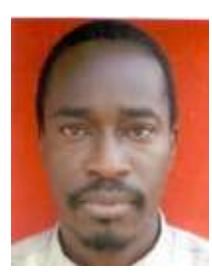

Sunday B. Alabi holds B.Sc. (1998) and M.Sc. (2005) in Chemical Engineering from the Obafemi Awolowo University, Ile-Ife, Nigeria. He holds a Ph.D. (2011) in Chemical and Process Engineering from the University of Canterbury, Christchurch, New Zealand.

Dr. Alabi's research interests include process modelling, control \& optimization, soft sensing, and rheology of complex fluids. He is a COREN-registered Engineer, member of the Nigerian Society of Chemical Engineers (MNSChE), as well as Nigerian Society of Engineers (MNSE). 